\title{
Authentic Leadership and Behavioral Integrity as Drivers of Follower Commitment and Performance
}

\author{
Hannes Leroy \\ Research Center of Organization Studies, \\ Katholieke Universiteit Leuven, Naamsestraat 69, 3000 Leuven, Belgium \\ Michael E. Palanski \\ Rochester Institute of Technology, Rochester, NY, USA \\ Tony Simons \\ Cornell University, Ithaca, NY, USA
}

\begin{abstract}
The literatures on both authentic leadership and behavioral integrity have argued that leader integrity drives follower performance. Yet, despite overlap in conceptualization and mechanisms, no research has investigated how authentic leadership and behavioral integrity relate to one another in driving follower performance. In this study, we propose and test the notion that authentic leadership behavior is an antecedent to perceptions of leader behavioral integrity, which in turn affects follower affective organizational commitment and follower work role performance. Analysis of a survey of 49 teams in the service industry supports the proposition that authentic leadership is related to follower affective organizational commitment, fully mediated through leader behavioral integrity. Next, we found that authentic leadership and leader behavioral integrity are related to follower work role performance, fully mediated through follower affective organizational commitment. These relationships hold when controlling for ethical organizational culture.
\end{abstract}

\section{Keywords}

Affective organizational commitment • Authentic leadership • Behavioral integrity • Ethical organizational culture $\bullet$ Work role performance

To thine own self be true, And it must follow, as the night the day, Thou canst not then be false to any man.-Polonius, in William Shakespeare's Hamlet, Act I, Scene 3 
As Shakespeare explains in a father's advice to his son, being true to oneself-or authentic-is an important precondition to being true to others-to keep one's word, and not to misrepresent oneself (see also Bass and Bass 2008, p. 223). In the last decade or so, these ideas have been examined within the context of business ethics (Driscoll and McKee 2007; Jackson 2005; Liedtka 2007; Verbos et al. 2007), particularly within the study of leader integrity (Palanski and Yammarino 2007; Palanski et al. 2011). Specifically, the idea of "being true to oneself" has manifested itself in of the form of authentic leadership, which focuses on those behaviors that indicate that leaders are self-aware and regulate the self accordingly (Avolio and Gardner 2005). Similarly, the idea of "being true to one's word when dealing with others" has manifested itself as behavioral integrity, the perceived alignment between an actor's words and actions (Simons 2002).

Both authentic leadership and leader behavioral integrity have been examined under the broader umbrella of leader integrity as those positive virtues that are important in characterizing leadership character (Palanski and Yammarino 2007). In this context, both behavioral integrity and authentic leadership have been posited to form a "root construct" (Avolio and Gardner 2005) or a "key ingredient" (Simons 1999) of other positive forms of leadership. To be more exact, both authentic leadership and behavioral integrity have been placed within the broader umbrella of positive organizational behavior or positive organizational scholarship (Luthans and Youssef 2007; Simons et al. 2011). This positive lens on human behavior in the workplace identifies those human strengths that drive effective performance in today's complex and unstable work environment (Bakker and Schaufeli 2008).

Previous research has confirmed that authentic leadership and behavioral integrity predict similar measures of follower performance through similar theoretical mechanisms. Authentic leadership has been demonstrated to drive follower affective organizational commitment, performance, and organizational citizenship behaviors through trust in the leader and identification with the leader (Walumbwa et al. 2008, 2010, 2011). Similarly, behavioral integrity has been demonstrated to drive follower performance and organizational citizenship behaviors through perceived trust in and satisfaction with the leader, and follower affective organizational commitment (Dineen et al. 2006; Palanski and Yammarino 2011; Simons et al. 2007).

Despite these similarities, authentic leadership and behavioral integrity are not the same (Palanski and Yammarino 2007). Authentic functioning is primarily inwardfocused reflecting behaviors that indicate whether one remains true to oneself (Kernis 2003; Jackson 2005), while behavioral integrity is primarily outward-focused, as others' perceptions of alignment between word and deeds (Simons 2002). In this article, we follow this reasoning and further clarify Shakespeare's quote that "being true to oneself" helps leaders "walk the talk". Next, we argue that authentic leadership and behavioral integrity build on similar theoretical mechanisms to foster follower performance (Avolio and Gardner 2005; Simons 2002). Specifically, we argue that authentic leadership and behavioral integrity foster follower identification with the organization, thus driving follower affective organizational commitment. In turn, affective organizational commitment helps us understand how leader integrity drives follower work role performance. Employees who are personally identified with the organization are willing 
to work hard, take initiative, and adapt to changes (Griffin et al. 2007; Meyer et al. 2004). We elaborate on our hypothesized conceptual model in Fig. 1 in the next paragraphs.

\section{Development of Hypotheses}

\section{Authentic Leadership and Leader Behavioral Integrity}

Walumbwa et al. (2008) identified and validated four components to describe authentic leadership. Self-awareness refers to demonstrating behaviors that indicate that leaders are aware of personal needs, preferences, motivations, and wants. Balanced processing refers to leader behavior that shows that leaders try to analyze relevant data before coming to a decision and that leaders are not afraid to solicit opposing views from followers. Relational transparency refers to presenting the leaders' authentic self, their true feelings, and thoughts to followers. Finally, internalized moral perspective refers to self-regulation that is guided by internal moral standards and values, and results in behaviors and decisions consistent with these internalized values. These components are based on the study of Kernis and Goldman (2006) who defined authentic functioning as 'the unobstructed operation of one's true, or core, self in one's daily enterprise" (Kernis 2003, p. 13) or, in other words, the extent that leaders remain true to oneself (Avolio and Gardner 2005). It is important to note that the term authentic functioning (and thus authentic leadership) refers to behaviors that make one authentic and that, in the case of authentic leadership, are observable to followers. This in distinct from perceptions of whether someone is authentic or genuine.

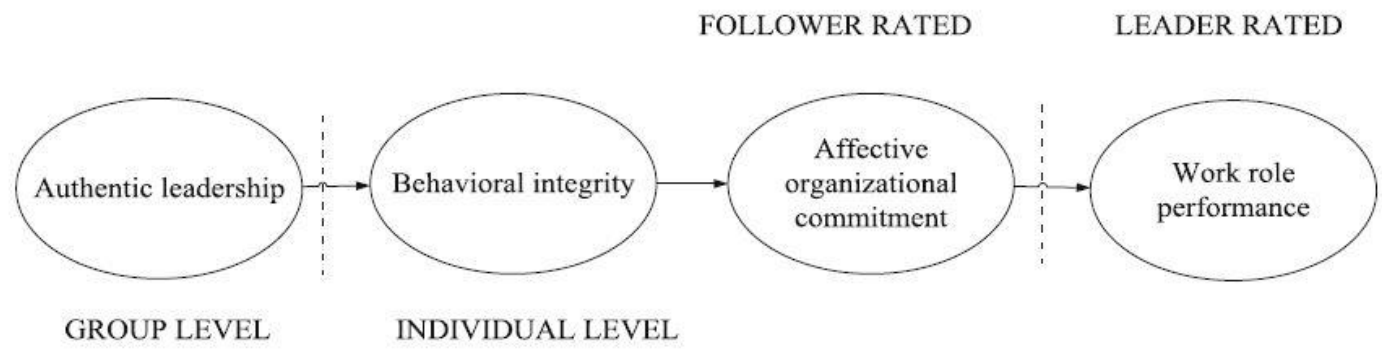

Fig. 1 Hypothesized model

Simons (2002) defines leader behavioral integrity (BI) as the perceived pattern of alignment between the leader's words and deeds or, in other words, the extent that leaders are seen as practicing what they preach. Simons $(2002,2008)$ argued that there are several factors that drive Bl. An important determinant is the extent to which the leader does, in fact, keep promises and enact espoused values. Specifically, the actual alignment between words and deeds is argued to be an important driver of perceived alignment. The actual alignment is further argued to be affected by the extent to which the leader is aware of personal values. A lack of self-awareness will result in the leader espousing values based on social pressure or practical exigencies-values that he or she might not deeply accept and so not fully enact. While actual alignment is important for $\mathrm{BI}$, it does not guarantee that followers will perceive $\mathrm{BI}$. $\mathrm{BI}$, because it is subjectively assessed, is also shaped by the extent to which leaders are transparent to followers about what they think, feel or believe. When managers do not communicate their values 
or communicate false values, this failure may lead to a perceived incongruence between what managers say and do.

Simons (2002) argues that some word-deed inconsistency will be inevitable. Managers typically need to satisfy diverse constituencies. Diverse role-expectations may lead to competing values and require the leader to occasionally renege on promises. If these breaches result in a perceived lack of behavioral integrity depends in part on how the leader communicates about the breaches. Leaders can engage in selfdefensive mechanisms by coming up with excuses, apologies, or dismissals. Simons (2008), however, suggests that the one of the best strategies to maintain perceptions of behavioral integrity is accepting personal responsibility for the broken promise and being transparent about the reasons behind the decision.

We believe these antecedents to follower perceptions of leader behavioral integrity are present in the conceptualization of authentic leadership. Authentic leadership comprises patterns of behavior that facilitate leaders' living by their words and being seen as doing so: Authentic leaders are by definition more aware of the values that drive their decisions - which makes them better able to describe those values accurately and so align their words and actions. Authentic leaders are also more likely to communicate openly about those values, and to apologize when their actions fall short of those espoused values. These two behavior patterns enhance follower perceptions of leader behavioral integrity, as they provide context and explanation for the leader's actions and any emergent inconsistencies. Thus, the components of authentic leadership facilitate both leaders' follow-through on their word and their communication about that follow-through. Based on this reasoning, we advance the following hypothesis:

Hypothesis 1 Authentic leadership behavior is positively related to follower perceptions of leader behavioral integrity.

\section{Authentic Leadership, Leader Behavioral Integrity and Affective Organizational Commitment}

Affective organizational commitment can be described as the employee's positive emotional attachment and identification with the organization (Allen and Meyer 1990). Avolio and Gardner (2005) suggest that we can understand the relationship between authentic leadership and follower affective organizational commitment through the theoretical mechanisms of positive social exchanges and personal and social identification of the follower with the leader. Authentic leaders interact in an open and non-defensive way-and thus present themselves to followers as vulnerable. This vulnerability engenders in followers trust in leaders and their willingness to be vulnerable (Walumbwa et al. 2011). This reciprocal, trusting relationship between leaders and follower sets the stage for personal and social identification between followers and leaders (Walumbwa et al. 2010). Followers will get to know, understand, and value their leader's personality, wants, needs, and desires (personal identification), as well as their role-position as a leader and thus as a representative spokesperson for the overall organization (social identification). This identification will impact follower's affective organizational commitment (Avolio et al. 2004). 
We believe these effects of authentic leadership on affective organizational commitment can be better understood by considering the concept of behavioral integrity. Behavioral integrity was posited to be an important driver of employee affective organizational commitment for two reasons (Simons 2008). First, by following up on promises, high behavioral integrity leaders indicate to followers that trust in the leaders is warranted. Second, in consistently conveying the same values through words and actions, the leader clearly and unequivocally communicates what he or she truly values in work-related behavior, thus presenting the basis of personal and social identification of the follower with the leader. The combination of direct and sincere communication of values and follow-up on promises and behavioral consequences of these valuestatements will lead the follower to identify with the leader and the values he or she, as the primary face of the organization (Grojean et al. 2004), stands for.

Based on these theoretical arguments, we expect that perceptions of behavioral integrity will mediate the effect of authentic leadership on follower affective organizational commitment. We expect that authentic leader behaviors will engender follower perceptions that this leader walks the talk (see Hypothesis 1) and that these perceptions are responsible for follower trust in and identification with the leader and the organization as a whole. In further support of this reasoning, previous research has identified that leader behavioral integrity is an important antecedent to trust in the leader (Palanski and Yammarino 2011; Simons et al. 2007) and follower affective organizational commitment (Simons and McLean-Parks 2000). In addition, authentic leadership has been shown to be related to follower affective commitment (Walumbwa et al. 2008), group trust (Walumbwa et al. 2011), and identification with one's supervisor (Walumbwa et al. 2010).

Hypothesis 2 Behavioral integrity mediates the relationship between authentic leadership and follower affective organizational commitment.

\section{Leader Integrity, Follower Affective Organizational Commitment, and Work Role Performance}

Griffin et al. (2007) defined follower work role performance as proficient, adaptive, and pro-active work behaviors and argued that these behaviors are particularly effective in an uncertain work environment. Both the literature on behavioral integrity (Simons 1999) and authentic leadership (Avolio and Gardner 2005) have argued that leader integrity is especially important in a turbulent work environment. In a complex and highly volatile environment, it is important for leaders to offer stability by promoting clear directions and values for followers to identify with. In support of a positive relationship between leader integrity and follower work role performance, the previous research has indicated that authentic leadership (Walumbwa et al. 2008, 2010) and leader behavioral integrity (Dineen et al. 2006; Palanski and Yammarino 2011; Simons and McLean-Parks 2000) are related to follower performance and organizational citizenship behaviors.

In this article, we further argue that the relationship between leader integrity and follower performance is mediated by follower's work experiences. To be more exact, we argue that affective organizational commitment mediates the relationship between 
leader integrity and work role performance. To understand the relationship between follower affective organizational commitment and work role performance, it is important to understand that affective organizational commitment may reflect follower's intrinsic work motivation (Meyer et al. 2004). In contrast to other types of organizational commitment (i.e., continuance commitment and normative commitment), employees who experience affective commitment pursue work-related goals because they want to not because they feel they have to. Gagne' and Deci (2005) offer that follower intrinsic work motivation may be especially important in driving the in-role and extra-role behaviors that are important in the current work environment. In personally valuing the importance of their work, employees will be more likely not only to work hard at their standard work tasks but also to remain open to changes and take personal initiative. In further support of this reasoning, previous research has shown that follower intrinsic work motivation in general (Gagne' and Deci, 2005) and follower affective organizational commitment in particular (Meyer et al. 2002; Griffin et al. 2007) are related to follower performance and organizational citizenship behaviors.

In this study, we hypothesize that affective organizational commitment will mediate the relationship between leader behavioral integrity and follower work role performance. Followers will personally identify with a behaviorally integer leader and thus become more intrinsically motivated for their work tasks. In turn, this intrinsic work motivation will drive their work role performance. We hypothesize as follows:

Hypothesis 3 The effects of leader integrity on follower work role performance are mediated by follower affective organizational commitment.

\section{Method \\ Sample and Procedure}

We collected data from 25 organizations in Belgium to test our hypotheses. Participating companies were small- to medium-sized organizations in the service industry. These organizations fit the purpose of our study in that these organizations may show meaningful variance on our dependent variable of work role performance. Within these organizations, our sampling design focused on selecting followers and leaders within teams. We considered a team to consist of one team leader and a minimum of four team members who reported directly to this leader.

Company representatives provided the e-mail addresses of 345 followers and 49 team leaders to the researchers and informed the team leaders and followers about the study. We contacted respondents through email, asked them to complete an internet survey, and reminded them after 2 weeks. Participation was voluntary, and respondents were assured that we would only report aggregated results. We administered the survey at two stages. At stage 1, a total of 252 followers or $73 \%$ completed the survey. At Stage 2, 1 month later, team leaders were asked to rate the performance of followers. Participating companies asked us to restrict leader-rated performance to four randomly selected team members to avoid placing an excessive work load on leaders. Thirty team leaders $(61 \%)$ completed the survey after reminders. The total number of team members for whom leader performance ratings were provided was 118 . 
The average number of years that our sample of leaders had served as a leader for their team was 5.50 years $(S D=5.31)$. Seventy percent of the leaders held graduate degrees, $60 \%$ were men, and their average age was 40 years $(S D=7.99)$. On average, the organizational tenure of our sample of team members was 9.95 years $(S D=8.93)$, and their mean age was 36.26 years $(S D=9.34)$. Thirty-seven percent of the followers held graduate degrees and $70 \%$ were women. To rule out potential non-response bias, we examined and found no differences $(p>0.05)$ between followers whose leaders did and did not participate at Stage 2.

\section{Measures \\ Authentic Leadership}

Walumbwa et al. (2008) validated a 16-item operational definition of authentic leadership. Followers were asked to rate the leader on a five-point Likert scale ranging from never to almost always. Sample items include "Is eager to receive feedback to improve interactions with others" (self-awareness), "Is willing to admit mistakes when they are made" (relational transparency), "Makes decisions based on his/her core beliefs" (internalized moral perspective), and "Solicits views that challenge his or her deeply held positions." (balanced processing).

\section{Behavioral Integrity}

Simons and McLean-Parks (2000) developed an eight-item measure on perceived behavioral integrity that was reported in Simons et al. (2007). Four items deal with promisekeeping behavior, and the other four items deal with enactment of espoused values. Items were measured on a five-point Likert scale ranging from completely agree to completely disagree. Sample items are "My manager delivers on promises." and "My manager practices what he/she preaches".

\section{Affective Organizational Commitment}

Affective organizational commitment was assessed by the Meyer et al. (1993) affective organizational commitment scale. Followers were asked to respond to six items on a seven-point Likert scale ranging from strongly disagree to strongly agree. An example item is "I feel emotionally attached to my organization."

\section{Work Role Performance}

Griffin et al. (2007) validated a measure of individual work role performance for the benefit of the overall organization. We included nine items measuring proficiency "Presented a positive image of the organization to other people," adaptivity "Responded flexibly to overall changes in the organization (e.g., changes in management)" and proactivity "Made suggestions to improve the overall effectiveness of the organization (e.g., by suggesting changes to administrative procedures)". We asked leaders to rate their frequency using a five-point Likert scale, with anchors ranging from never to almost always. 


\section{Control Variables}

We controlled for demographic information of employees, such as age, sex, and tenure, with the organization. Furthermore, previous research has suggested that a positive ethical climate might be related to authentic leadership and behavioral integrity (Avolio and Gardner 2005; Driscoll and McKee 2007; Simons 2008; Verbos et al. 2007) and may, therefore, confound the relationship between these constructs and their affective organizational commitment. In this study, we included three dimensions of the measure an ethical culture developed by Kaptein $(2008,2011)$ : discussability, transparency, and sanctionability. Example items are discussability ("In my immediate work environment, I have the opportunity to express my opinion"), transparency ("If a colleague does something which is not permitted, my manager will find out about it"), and sanctionability ("In my immediate work environment, people are held accountable for their actions"). We asked employees to rate 18 items on a seven-point Likert scale ranging from completely agree to completely disagree.

\section{Analysis}

We analyzed the data using structural equation modeling in two steps (McDonald and Ho 2002). First, we conducted a confirmatory factor analysis on our measurement model. Second, we tested the structural, hypothesized relationships between the variables. Specifically, we tested the hypothesized relationships in a multilevel path model using scores of authentic leadership aggregated to the group level (Walumbwa et al. 2010). Multilevel structural equation modeling takes into account the fact that employees are nested within teams and are thus non-independent. Multilevel structural equation modeling is thus similar to the procedures used in hierarchical linear modeling but adds information on how the hypothesized model fits the data (Kline 2011). We performed these analyses using the M-plus statistical package (Muthen and Muthen 2011).

\section{Results}

\section{Measurement Model and Descriptive Statistics}

We performed a confirmatory factor analysis to validate the higher-order factor structure of authentic leadership and follower work role performance. We found a reasonable fit for a higher-order factor model for authentic leadership (Hu and Bentler 1999): $x^{2}(100)=133.41(p<0.05), \mathrm{SRMR}=0.06, \mathrm{RMSEA}=0.08, \mathrm{CFI}=0.95$. We also found a good fit for a higher-order factor model for leaderrated work role performance: $x^{2}(24)=33.20(p=0.10), \mathrm{SRMR}=0.05, \mathrm{RMSEA}=0.05, \mathrm{CFI}=0.98$. To validate the overall measurement model, we used item parcels to maintain a favorable indicator-tosample-size ratio. More specifically, we followed the recommendations of Little et al. (2002) and created four domain-representative parcels for authentic leadership and follower work role performance and four random parcels for behavioral integrity, and three for affective organizational commitment. A confirmatory factor analysis showed a good fit for a model where all items load on their respective factors: $x^{2}(59)=91.03$ 
(pl0.05), SRMR $=0.03, \mathrm{RMSEA}=0.06, \mathrm{CFI}=0.98$. This model showed a significantly better fit than a model where authentic leadership and behavioral integrity load on the same factor: $x^{2}(62)=285.51(p<0.05)$, SRMR $=0.07$, RMSEA $=0.15, \mathrm{CFI}=0.90$. Table 1 depicts the means, standard deviations, correlations, and Cronbach alphas of all the variables included in this study. The correlation matrix depicts significant correlations between the variables considered under our hypotheses in the expected direction. Authentic leadership and behavioral integrity are positively correlated, and behavioral integrity is more highly correlated with follower affective organizational commitment than is authentic leadership. In turn, organizational commitment is correlated more highly with leader-ratings of follower work role performance than either authentic leadership or leader behavioral integrity.

\section{Path Model}

We tested our hypothesized model by estimating a path model where authentic leadership influences follower affective organizational commitment through leader behavioral integrity. Follower affective organizational commitment further drives follower work role performance. Because our interest lies in authentic leadership behaviors as they are displayed uniformly to different team members, we averaged this measure within work groups (Walumbwa et al. 2010). Supporting this aggregation, we found an average $r_{w g}$ of $0.82(M d n=0.82)$ showing adequate within-group agreement, an intraclass correlation coefficient of $\operatorname{ICC}(1)=0.28$ and $\operatorname{ICC}(2)=0.67$ (Bliese 2000). An analysis of variance (ANOVA) further indicated a significant amount of between-group variance $F(48,203)=3.01, p=0.01$ in authentic leadership. In order to conduct our cross-level effects, we examined and found a significant $(p<0.01)$ amount of betweengroup variance in behavioral integrity, affective organizational commitment, and work

Table 1 Mean, standard deviations, reliabilities, and correlations among the study variables

\begin{tabular}{|c|c|c|c|c|c|c|c|c|c|c|}
\hline Variables & Mean & SD & 1 & 2 & 3 & 4 & 5 & 6 & 7 & 8 \\
\hline 1. Sex $(1=$ female; $0=$ male $)$ & 0.70 & 0.46 & I & & & & & & & \\
\hline 2. Org tenure (years) & 9.95 & 8.94 & 0.03 & I & & & & & & \\
\hline 3. Age (years) & 36.26 & 9.34 & -0.02 & $0.74 * *$ & I & & & & & \\
\hline 4. Ethical org culture & 3.54 & 0.58 & $0.18^{* *}$ & 0.01 & 0.04 & 0.93 & & & & \\
\hline 5. Authentic leadership & 3.32 & 0.72 & 0.08 & -0.13 & -0.12 & $0.51 * *$ & 0.95 & & & \\
\hline 6. Behavioral integrity & 3.82 & 0.70 & -0.04 & 0.07 & 0.10 & $0.42 * *$ & $0.66 * *$ & 0.90 & & \\
\hline 7. Affective org commitment & 5.40 & 0.82 & $0.14 *$ & $0.19 * *$ & $0.14^{*}$ & $0.34 * *$ & $0.25 * *$ & $0.28 * *$ & 0.90 & \\
\hline 8. Work role performance & 3.97 & 0.60 & 0.11 & 0.02 & 0.07 & $0.27 * *$ & $0.22 *$ & $0.22 *$ & $0.41 * *$ & 0.87 \\
\hline
\end{tabular}

Note: Reliability estimates for scales are presented in bold on the diagonal. org organizational. $N$ equals 225 for all variables except for work role performance where the $N$ size is 118

$* p<0.05$ (2-tailed)

** $p<0.01$ (2-tailed)

role performance: $41 \%$ of the variance in behavioral integrity, $37 \%$ of the variance in affective organizational commitment, and $46 \%$ of the variance in leader-rated work role performance resided between groups. The final results for our hypothesized model showed a good fit: $x^{2}(1)=3.70(p=0.05)$, SRMR within $=0.06$, SRMR between $=0.01$, $\mathrm{RMSEA}=0.10, \mathrm{CFI}=0.96$. 
Hypothesis 1 predicted that authentic leadership would be significantly related to leader behavioral integrity. Our results indicated that authentic leadership is significantly related to leader behavioral integrity $(\hat{y}=0.27, p<0.05)$. Hypothesis 2 predicted that perceptions of behavioral integrity mediate between authentic leadership and follower affective organizational commitment. We found that leader behavioral integrity was significantly related to follower affective organizational commitment $(\hat{y}=0.25, p<0.05)$. To test the cross-level mediation effect, we followed the recommendations of Zhang et al. (2009) who argued that cross-level mediation effects may be confounded if one looks at within-level effects as mediators rather than between-group effects. As such, the indirect effect was calculated with the aggregated scores of behavioral integrity on follower affective organizational commitment. We conducted a Sobel test on this indirect effect and found that this effect was significant $z=3.35(p<0.05)$. We thus confirm hypothesis 2 that the effects of authentic leadership on follower affective organizational commitment is mediated by behavioral integrity. Hypothesis 3 predicted that leader integrity is significantly related to follower work role performance through follower affective organizational commitment. Our model indicates that affective organizational commitment is significantly related to follower work role performance $(\hat{y}=0.27, p<$ $0.05)$. The proposed mediation effect of behavioral integrity on follower work role performance was supported by a Sobel test $z=3.86(p<0.05)$. These results hold when controlling for ethical organizational culture, sex, age, and tenure.

We specified a number of alternative models to further validate these findings. We summarize the fit of these models in Table 2. First, we specified a model where authentic leadership has a direct effect on follower affective organizational commitment. Despite a positive initial correlation between both (see Table 1), the parameter from authentic leadership to follower affective organizational commitment was not significant $(\hat{y}=0.03 ; p=0.86)$. This analysis suggests that leader behavioral integrity fully mediates this effect. Second, we specified a model where authentic leadership has a direct effect on follower work role performance. Adding this additional path rendered the parameter from authentic leadership to follower work role performance non-significant ( $\hat{y}$ $=0.05 ; p=0.45)$. Third, we specified a model where behavioral integrity has a direct effect on follower work role performance. Despite the initial correlation, the parameter from behavioral integrity to follower work role performance was insignificant ( $\hat{y}=0.15 ; p$ $=0.05$ ). These effects further validate that affective organizational commitment fully mediates the effects of leader behavioral integrity on follower performance.

\section{Discussion}

In this article, we set out to increase our understanding of how authentic leadership and behavioral integrity relate to each another and how both contribute to effective performance in the current, turbulent work environment. First, we demonstrated that authentic leadership is related to leader behavioral integrity. Leaders who remain true to the self in their behavior, and are open and non-defensive in their interaction with others, will be perceived as walking the talk, delivering on promises, and aligning words and deeds. Second, we demonstrate that authentic leadership is related to follower affective organizational commitment, fully mediated through perceptions of leader behavioral integrity. Authentic leadership drives follower identification with the 
organization because these leaders stay true to themselves, which facilitates their aligning of words and actions (BI), thus making it easier for followers to trust the leader and identify with the leader as the organizational spokesperson. Finally, we demonstrated that leader integrity is related to follower work role performance and that this effect is fully mediated through follower affective organizational commitment. In a turbulent work environment, leader integrity offers stability by offering followers clear values to identify with. This personal identification of the follower with the organization drives their willingness not only to promote a good image of the organization, but also to adapt to changes and take initiative to improve the overall effectiveness of the organization.

\section{Contributions}

This article makes a number of contributions to the previous literature. First, we contribute to the literature on behavioral integrity. Behavioral integrity is an established construct that shows strong linkages to follower outcomes, yet little is known about its

Table 2 Fit indices for estimated path models

\begin{tabular}{llllr}
\hline Model & $\chi^{2}(\mathrm{df})$ & $\begin{array}{l}\text { SRMR } \\
\text { within }\end{array}$ & $\begin{array}{l}\text { SRMR } \\
\text { between }\end{array}$ & RMSEA \\
\hline $\begin{array}{l}\text { 1. Hypothesized model (see Fig. 1) } \\
\begin{array}{l}\text { 2. Hypothesized model + direct effect between authentic leadership } \\
\text { and affective organizational commitment }\end{array}\end{array}$ & $\begin{array}{l}3.70(1) \\
\begin{array}{l}\text { 3. Hypothesized model + direct effect between authentic leadership } \\
\text { and follower work role performance }\end{array}\end{array}$ & 0.06 & 0.01 & 0.10 \\
$\begin{array}{l}\text { 4. Hypothesized model + direct effect between behavioral integrity } \\
\text { and follower work role performance }\end{array}$ & $23.19 *$ & 0.06 & 0.01 & 0.30 \\
\hline
\end{tabular}

SRMR within standardized root-mean-square residual for the within groups part of the model, SRMR between standardized root-mean-square residual for the between groups part of the model, RMSEA root-mean-square error of approximation, CFI Comparative Fit Index

* $p<0.05$

behavioral antecedents (Simons et al. 2011). We propose and empirically verify authentic leadership as an antecedent to leader behavioral integrity. This result is important because it provides insight into how being true to the self may result in others' positive perceptions of aligning words and deeds. Specifically, our results suggest that being true to the self does not imply a rigid or dogmatic adherence to personal values. Being authentic refers to an open and non-defensive way of interacting with one's environment. As a result, leaders who function authentically express their personal-self yet, at the same time, remain open to relational input. As a result, individuals who function authentically will be perceived as having more integrity, not only because their words and deeds are actually aligned, but also because they effectively manage others' perception of how their words and deeds are in alignment.

Second, while authentic leadership has a broad and rich theoretical base, more research is needed on conceptual clarification and clarifying mechanisms of impact (Cooper et al. 2005). Authentic leadership was conceptualized as a multi-component construct (Walumbwa et al. 2008) suggesting different theoretical mechanisms (Avolio and Gardner 2005). By looking at behavioral integrity as an outcome to authentic leadership and mediator to follower outcomes, we further clarify the conceptual (Walumbwa et al. 2008) and theoretical (Walumbwa et al. 2010, 2011) underpinnings of 
authentic leadership. We offer that being true to the self will yield behaviors that support follower perceptions of word-action alignment: self-awareness and internal consistency support actual alignment, and transparent communications additionally support perceptions of alignment, especially in ambiguous situations. Behavioral integrity is an important mechanism of authentic leadership as it clarifies how authentic leadership is related to follower affective commitment to the organization.

Finally, these results further clarify how leader integrity is related to follower work role performance (Palanski and Yammarino 2011). We demonstrated how leader behavioral integrity is important in driving effective performance in a turbulent work environment. We argued that in a world that is subject to constant change, it is important for leaders to stay true to themselves and walk the talk. To use a metaphor, integral leaders offer followers more stability for followers in an otherwise unstable work environment. Specifically, we argue that integral leaders offer more stability to followers by staying true to the values they espouse, thus offering clear signals about what behaviors are expected from followers.

\section{Limitations}

There are a number of limitations of our study, which should be acknowledged. First, because most of the data are cross-sectional in nature, we are unable to draw strong causal inferences regarding the direction of the relationships identified. Additional studies that employ longitudinal research designs are needed to determine with greater confidence the direction of the relationship among the variables studied in this article.

Second, the antecedent and mediating variables in our study were rated by the same-source followers. Same-source data are a potential limitation because they introduce the chance that these findings can be attribute to common method variance (Podsakoff et al. 2003). Research suggests that concerns for common-method bias can be reduced by the adoption of several pro-active strategies (Lindell and Whitney 2001; Podsakoff et al. 2003): In this study, we used leader-ratings of follower performance as an externally validated dependent variable (follower work role performance). In addition, we used a multilevel research design that confirmed the existence of some of the posited effects at the group level of analysis, reducing biasing effects that are operative at the individual level of analysis. Nevertheless, future research should include multiple raters at different time periods to reassess the relationships identified in our study.

A third limitation pertains to the generalizability of our findings. Our participants were restricted to employees in small-to-medium-sized service companies in Belgium. Future investigations could assess the generalizability of our findings by drawing samples from individuals in other organizational environments or national cultures. For example, we acknowledge that the results of this study need to be reconfirmed in other national cultures where being true to the self is of less value or where word-deed misalignments are perceived differently. In addition, future research could reassess the present findings in other dynamic work environment such as health care. In this context, it may be interesting to demonstrate how authentic leadership and behavioral integrity are related to context-specific measures of performance such as safety problems.

\section{Future Directions}


The present findings can be expanded in a number of ways. Future research may want to look at other antecedents to leader behavioral integrity. One particularly interesting antecedent is leader political skills. Simons (2008) suggested that leader behavioral integrity will be a function of the aptitude of the leader to communicate effectively to followers. Intuitively, one may argue that leader political skills and authentic leadership are at the opposite ends of the same continuum. Leaders who remain true to the self do not try to manipulate followers into a certain course of action. However, this is a particularly negative view on leader political skills that do not coincide with recent conceptualizations (Ferris et al. 2005, 2007). As we noted in this article, a leader often needs to address the needs of diverse constituencies and therefore needs to be careful in how they present an argument. Being careful about how to phrase an argument might not always be about political skills so much, as it might also be an effort of the leader or politician to remain true to the self. In this case, authentic leadership and leader political skills need not be opposites, but might mutually reinforce one another and perceptions of leader behavioral integrity. A similar suggestion has been offered by Douglas et al. (2005), but has not been empirically tested.

Future research could look at alternative measures of follower motivation which explain the effect of leader integrity on follower outcomes. One specific example is follower work engagement as the extent to which individuals can express their own- or true-self at work (Meyer and Gagne 2008). Work engagement may lead to similar effect on performance as affective organizational commitment but may be directed more at behaviors that are important for one's job or team rather than the overall organization (Griffin et al. 2007). We further expect that authentic leadership will have a direct effect on follower engagement over and above leader behavioral integrity. Authentic leadership create an environment where followers can be themselves. In support of this reasoning, Walumbwa et al. (2010) found that both feelings of empowerment as well as identification explain the effect of authentic leadership on follower engagement.

Finally, while our operational definition of authentic leadership explicitly includes a moral component (Walumbwa et al. 2008), the previous research has questioned whether authentic leadership (Sparrowe 2005) or leader behavioral integrity (Palanski and Yammarino 2007) should include a moral component. Can one be an authentic or integer narcissist, and if so what are the consequences of being an authentic or integer narcissist? Future research could investigate how leader benevolence (social versus egocentric orientation) combines with leader authenticity and behavioral integrity (leader word-deed alignment versus misalignment) to impact perceptions of trust in and effectiveness of leaders. 


\section{References}

Allen, N. J., \& Meyer, J. P. (1990). The measurement and antecedents of affective, continuance and normative commitment to the organization. Journal of Occupational Psychology, 63, 1-18.

Avolio, B. J., \& Gardner, W. L. (2005). Authentic leadership development: Getting to the root of positive forms of leadership. The Leadership Quarterly, 16, 315-338.

Avolio, B. J., Gardner, W. L., Walumbwa, F. O., Luthans, F., \& May, D. R. (2004). Unlocking the mask: A look at the process by which authentic leaders impact follower attitudes and behaviors. The Leadership Quarterly, 15, 801-823.

Bakker, A. B., \& Schaufeli, W. B. (2008). Positive organizational behaviour: Engaged employees in flourishing organizations. Journal of Organizational Behavior, 29, 147-154.

Bass, B. M., \& Bass, R. (2008). The Bass handbook of leadership. Theory, research, \& managerial applications. New York: Free Press.

Bliese, P. D. (2000). Within-group agreement, non-independence, and reliability: Implications for data aggregation and analysis. In K. Klein \& S. Kozlowski (Eds.), Multilevel theory, research, and methods in organizations. San Francisco: Jossey Bass.

Cooper, C. D., Scandura, T. A., \& Schriesheim, C. A. (2005). Looking forward but learning from our past: Potential challenges to developing authentic leadership theory and authentic leaders. The Leadership Quarterly, 16, 475-493.

Dineen, B. R., Lewicki, R. J., \& Tomlinson, E. C. (2006). Supervisory guidance and behavioral integrity: Relationships with employee citizenship and deviant behavior. Journal of Applied Psychology, 91, 622-635.

Douglas, C., Ferris, G. F., \& Perrewe', P. L. (2005). Leader political skill and authentic leadership. In W. L. Gardner, B. J. Avolio, \& F. O. Walumbwa (Eds.), Authentic leadership theory and practice: Origins effects and development. Oxford: Elsevier.

Driscoll, C., \& McKee, M. (2007). Restorying a culture of ethical and spiritual values: A role for leader storytelling. Journal of Business Ethics, 73, 205-217.

Ferris, G. R., Treadway, D. C., Kolodinsky, R. W., Hochwarter, W. A., Kacmar, C. J., Douglas, C., et al. (2005). Development and validation of the political skill inventory. Journal of Management, 31, 126-152.

Ferris, G. R., Treadway, D. C., Perrewe', P. L., Brouer, R. L., Douglas, C., \& Lux, S. (2007). Political skill in organizations. Journal of Management, 33, 290-320.

Gagne, M., \& Deci, E. L. (2005). Self-determination theory and work motivation. Journal of Organizational Behavior, 26, 331-362.

Griffin, M., Neal, A., \& Parker, S. (2007). A new model of work role performance: Positive behaviors in uncertain and interdependent contexts. Academy of Management Journal, 50, 327-347.

Grojean, M. W., Resick, C. J., Dickson, M. W., \& Smith, D. B. (2004). Leaders, values and organizational climate: Examining leadership strategies for establishing an organizational climate regarding ethics. Journal of Business Ethics, 55, 223-241. 
Hu, L., \& Bentler, P. M. (1999). Cutoff criteria for fit indexes in covariance structure analysis: Conventional criteria versus new alternatives. Structural Equation Modeling, 6, 1-55.

Jackson, K. T. (2005). Towards authenticity: A sartrean perspective on business ethics. Journal of Business Ethics, 58, 307-325.

Kaptein, M. (2008). Developing and testing a measure for the ethical culture of organizations: The corporate ethical virtues model. Journal of Organizational Behavior, 29, 23-947.

Kernis, M. H. (2003). Toward a conceptualization of optimal self- esteem. Psychological Inquiry, 14, 1-26.

Kernis, M. H., \& Goldman, M. B. (2006). A multicomponent conceptualization of authenticity: Theory and research. Advances in Experimental Psychology, 38, 283-357.

Kline, R. B. (2011). Convergence of structural equation modeling and multilevel modeling. In M. Williams (Ed.), Handbook of methodological innovation. Thousand Oaks, CA: Sage.

Liedtka, J. (2007). Strategy making and the search for authenticity. Journal of Business Ethics, 80, 237-248.

Lindell, M., \& Whitney, D. J. (2001). Accounting for common method variance in crosssectional research designs. Journal of Applied Psychology, 86, 114-121.

Little, T. D., Cunningham, W. A., Shahar, G., \& Widaman, K. F. (2002). To parcel or not to parcel: Exploring the question, weighing the merits. Structural Equation Modeling, 9, 151-173.

Luthans, F., \& Youssef, C. M. (2007). Emerging positive organizational behavior. Journal of Management, 33, 321-349.

McDonald, R. P., \& Ho, M. R. (2002). Principles and practices in reporting structural equation analyses. Psychological Methods, 7, 64-82.

Meyer, J. P., Allen, N. J., \& Smith, C. A. (1993). Commitment to organizations and occupations-extension and test of a 3-com- ponent conceptualization. Journal of Applied Psychology, 78, 538-551.

Meyer, J. P., Becker, T. E., \& Vandenberghe, C. (2004). Employee commitment and motivation: A conceptual analysis and integra- tive model. Journal of Applied Psychology, 89, 991-1007.

Meyer, J. P., \& Gagne', M. (2008). Employee engagement from a self-determination theory perspective. Industrial and Organizational Perspectives, 1, 60-62.

Meyer, J. P., Stanley, D. K., Hersovitch, L., \& Topolnytsky, L. (2002). Affective, continuance, and normative commitment to the organization: A meta-analysis of antecedents, correlates and consequences. Journal of Vocational Behavior, 61, 20-52.

Muthen, L. K., \& Muthen, B. O. (2011). Mplus user's guide (6th ed.). Los Angeles, CA: Muthen \& Muthen.

Palanski, M. E., Kahai, S. S., \& Yammarino, F. J. (2011). Team virtues and performance: An examination of transparency, behavioral integrity, and trust. Journal of Business Ethics, 99, 201-216.

Palanski, M. E., \& Yammarino, F. J. (2007). Integrity and leadership: Clearing the conceptual confusion. European Management Journal, 25, 171-184. 
Palanski, M. E., \& Yammarino, F. J. (2011). Impact of behavioral integrity on follower job performance: A three-study examina- tion. The Leadership Quarterly, 22, 765-786.

Podsakoff, P. M., Mackenzie, S. B., Lee, J., \& Podsakoff, N. P. (2003). Common method biases in behavioral research: A critical review of the literature and recommended remedies. Journal of Applied Psychology, 88, 879-903.

Simons, T. L. (1999). Behavioral integrity as a critical ingredient for transformational leadership. Journal of Organizational Change Management, 12, 89-104.

Simons, T. L. (2002). Behavioral integrity: The perceived alignment between managers' words and deeds as a research focus. Organization Science, 13, 18-35.

Simons, T. L. (2008). The integrity dividend: Leading by the power of your word. Jossey Bass: San Francisco.

Simons, T. L., Friedman, R., Liu, L. A., \& McLean-Parks, J. (2007). Racial differences in sensitivity to behavioral integrity: Attitudinal consequences, in-group effects, and "trickle down" among black and non-black employees. Journal of Applied Psychology, 92, 650-665.

Simons, T. L., \& McLean-Parks, J. (2000). The sequential impact of behavior integrity on trust, commitment, discretionary service behavior, customer satisfaction, and profitability. Paper presented at the annual Academy of Management Conference, Toronto, ON.

Simons, T., Tomlinson, E., \& Leroy, H. (2011). Research on behavioral integrity: A promising construct for positive organizational scholarship. In K. S. Cameron \& G. M. Spreitzer (Eds.), Handbook of positive organizational scholarship. Oxford, UK: Oxford University Press.

Sparrowe, R. (2005). Authentic leadership and the narrative self. The Leadership Quarterly, 16(3), 419-439.

Verbos, A. K., Gerard, J. A., Forshey, P. R., Harding, C. S., \& Miller, J. S. (2007). The positive ethical organization: Enacting a living code of ethics and ethical organizational identity. Journal of Business Ethics, 76, 17-33.

Walumbwa, F. O., Avolio, B. J., Gardner, W. L., Wernsing, T. S., \& Peterson, S. J. (2008). Authentic leadership: Development and analysis of a multidimensional theory-based measure. Journal of Management, 34, 89-126.

Walumbwa, F. O., Luthans, F., Avey, J., \& Oke, A. (2011). Authentically leading groups: The mediating role of positivity and trust. Journal of Organizational Behavior, 34, 89-126.

Walumbwa, F. O., Wang, P., Wang, H., Schaubroeck, J., \& Avolio, B. J. (2010). Psychological processes linking authentic leadership to follower behaviors. The Leadership Quarterly, 21, 901-914.

Zhang, Z., Zyphur, M. J., \& Preacher, K. J. (2009). Testing multilevel mediation using hierarchical linear models: Problems and solutions. Organizational Research Methods, 12, 695-719. 